This item was submitted to Loughborough's Research Repository by the author.

Items in Figshare are protected by copyright, with all rights reserved, unless otherwise indicated.

\title{
The effect of school bag design and load on spinal posture during stair use by children
}

\author{
PLEASE CITE THE PUBLISHED VERSION
}

http://dx.doi.org/10.1080/00140139.2011.615415

PUBLISHER

(c) Taylor \& Francis

\section{VERSION}

AM (Accepted Manuscript)

\section{PUBLISHER STATEMENT}

This work is made available according to the conditions of the Creative Commons Attribution-NonCommercialNoDerivatives 4.0 International (CC BY-NC-ND 4.0) licence. Full details of this licence are available at: https://creativecommons.org/licenses/by-nc-nd/4.0/

\section{LICENCE}

CC BY-NC-ND 4.0

\section{REPOSITORY RECORD}

Hong, Youlian, Daniel Tik-Pui Fong, and Jing-Xian Li. 2019. "The Effect of School Bag Design and Load on Spinal Posture During Stair Use by Children”. figshare. https://hdl.handle.net/2134/21245. 


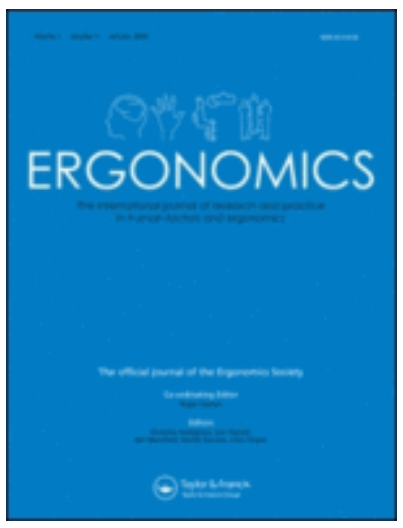

\section{The effect of school bag design and load on spinal posture during stair use by children}

\begin{tabular}{|r|l|}
\hline Journal: & Ergonomics \\
\hline Manuscript ID: & TERG-2011-0068.R3 \\
\hline Manuscript Type: & Original Article \\
\hline Author: & $\mathrm{n} / \mathrm{a}$ \\
\hline Complete List of Authors: & $\begin{array}{l}\text { Hong, Youlian; Chengdu Sports University, Department of Sports } \\
\text { Medicine } \\
\text { Fong, Daniel; The Chinese University of Hong Kong, Orthopaedics } \\
\text { and Traumatology }\end{array}$ \\
\hline Keywords: & $\begin{array}{l}\text { health care ergonomics < Application Domains, children < } \\
\text { Application Domains, biomechanics < Physical Ergonomics, physical } \\
\text { work capacity < Physical Ergonomics, musculoskeletal disorders < } \\
\text { Health and Safety }\end{array}$ \\
\hline
\end{tabular}

\section{SCHOLARONE Manuscripts}


Response to reviewer comment

Reviewer: 1

Comments to the Author

The authors have addressed many issues. However, the second major flaw, "2. The level of significance was not appropriately determined in this study. alpha=0.05 may not be an acceptable level of significance since multiple comparisons were conducted in the study," has not been fully addressed.

Response: The reviewer suggested that alpha $=0.05$ is not acceptable, as there are multiple comparisons in the study. I agree that multiple comparisons alone with each having alpha $=0.05$ is not acceptable, but before that, I have done a MANOVA with repeated measures on all parameters with alpha $=0.05$. This overall statistical analysis procedure has limited the uncertainly to only 5\%, and has avoid the accumulated uncertainly from multiple pairwise comparisons. Since this MANOVA showed significant effect (Wilk's lambda $=0.664, F=2.646, p=0.023$ ) then I proceed with the pairwise comparison. If it did not show a significant effect that the multiple comparisons would not be conducted. While $p<0.01$ is also a commonly used threshold, I comment that it could be slightly too conservative in a study with 13 subjects. I believe that $p<0.05$ is a well-accepted method and would like to keep such for those pairwise comparisons. I hope that the reviewer and editor could agree on my decision.

The $p$ values in the manuscript have not been reported in a consistent way: it was reported as " $p<0.05$," or " $p=0.0 x x$." The authors should report the exact numbers of the $p$ values unless the values are extremely small $(<0.0001)$. " $p<0.05 "$ is not a common way to report the $p$ value. The reviewer wants to see if the statement, "the authors commented that the level of significance was well achieved and the level of uncertainly was kept low," is valid.

Response: I have revised the table with the $p$ values of all pairwise comparison listed. Since the statistical analysis program show only to $p<0.001$, I could not fulfill the request of the reviewer to report one more decimal place to $p<0.0001$. I have tried my best to show all the information to support the study. Thanks to the reviewer for suggesting this, which could give the readers a better picture to understand the whole research result. 


\begin{tabular}{|c|c|}
\hline Title & $\begin{array}{l}\text { The effect of school bag design and load on spinal posture during } \\
\text { stair use by children }\end{array}$ \\
\hline Authors & Youlian HONG ${ }^{1}$, Daniel Tik-Pui FONG ${ }^{2}$, Jing Xian LI $^{3}$ \\
\hline $\begin{array}{l}\text { Affiliations and } \\
\text { postal addresses }\end{array}$ & $\begin{array}{l}{ }^{1} \text { Department of Sports Medicine, Chengdu Sports University, } \\
\text { Chengdu, China } \\
{ }^{2} \text { Department of Orthopaedics and Traumatology, Prince of Wales } \\
\text { Hospital, Faculty of Medicine, The Chinese University of Hong } \\
\text { Kong, Hong Kong, China } \\
{ }^{3} \text { School of Human Kinetics, Faculty of Health Sciences, University } \\
\text { of Ottawa, Ottawa, Canada }\end{array}$ \\
\hline $\begin{array}{l}\text { Corresponding } \\
\text { author }\end{array}$ & $\begin{array}{l}\text { Daniel Tik-Pui Fong dfong@ ort.cuhk.edu.hk } \\
\text { Department of Orthopaedics and Traumatology, Prince of Wales } \\
\text { Hospital, Faculty of Medicine, The Chinese University of Hong } \\
\text { Kong, Hong Kong, China }\end{array}$ \\
\hline Telephone & $\begin{array}{l}\text { Daniel Tik-Pui Fong (852) } 26323535 \\
\text { Youlian Hong (852) } 26096082\end{array}$ \\
\hline Facsimile & $\begin{array}{l}\text { Daniel Tik-Pui Fong (852) } 26463020 \\
\text { Youlian Hong (852) } 26035781\end{array}$ \\
\hline Email & $\begin{array}{l}\text { Daniel Tik-Pui Fong dfong@ ort.cuhk.edu.hk } \\
\text { Youlian Hong hongyoulian@gmail.com }\end{array}$ \\
\hline Running head & Load carriage during stair use \\
\hline
\end{tabular}




\begin{abstract}
:
Thirteen male childrenascending and descending stairs with loads that equaled $0 \%$, $10 \%, 15 \%$ and $20 \%$ of their body weight were the subject of our research: the boys were wearing an asymmetrical single-strap athletic bag or a symmetrical double-strap backpack during our experiments with them. The maximum spinal tilt to the loading side and to the support side, and the range of spinal motions, were obtained by using a motion analysis system. Our results showed that symmetry of spinal posture was observed both when they ascended staircasewith all loads and descended in a backpack. When carrying an athletic bag and when the load therein was $15 \%$ and $20 \%$ of the body weight when ascendingthe staircase, the lateral spinal tilt to the supporting side was significantly increased. We concluded that a symmetrical backpack with a load not exceeding $20 \%$ or an asymmetrical single-strap athletic bag with a load not exceeding $10 \%$ should be recommended for school children in order to promote safer staircase use.
\end{abstract}

Key Words:Biomechanics, Load-bearing, Carrying, Child, Orthopaedics, Gait

\title{
Statement of relevance:
}

Children carrying heavy school bags may develop spinal problems. This study suggested that, when they are using stairs, a symmetrical backpack with a load within $20 \%$ body weight is acceptable for them. When they are carrying an asymmetrical single-strap athletic bag, the bag's weight should not exceed $10 \%$ body weight in order to avoid excessive spinal tilt.

\section{Introduction:}

The wearing of heavy backpacks has prompted extensive discussion among children, 
parents and healthcare professionals about its potential to cause shoulder pain, neck pain and back pain and even spinal deformity (Mackenzie et al., 2003; Trevelyan and Legg, 2010). A recent study suggested that the weight of a school bag correlated with the magnitude of body sway, and that the increased body sway may be related to balance impairment and perhaps to a higher risk of falls (Pau and Pau, 2010). The weight of school bags in termsof the percentage of the body weight of children hasbeen reported as $17.7 \%$ in the United States (Pascoe et al., 1997), 20\% in Italy (Negrini and Carabalona, 2002) and 20\% in Hong Kong(Hong Kong Society for Child Health and Development). These heavy loads have caused spinal symptoms (Johnson et al., 1995), back pain (Sheir-Neiss et al., 2003), fatigue(Negrini and Carabalona, 2002), breathing restriction (Lai and Jones, 2001) and even acute injuries (Wiersema et al., 2003).

Numerous studies have been conducted to demonstrate the biomechanical effects of load carriage. In level overground walking and walking on a treadmill, a load of $15 \%$ body weight or more with a double-strap backpack significantly increased forward trunk lean (Hong and Cheung, 2003), prolonged blood pressure recovery time (Hong and Brueggemann, 2000), increased oxygen uptake and energy expenditure (Hong et al., 2000), increased breathing frequency ( $\mathrm{Li}$ et al., 2003), and increased trapezius muscle activity and fatigue (Hong et al., 2008). When the child was standing, the heavy load also altered the posture of a healthy subject (Chansirinukor et al., 2001), and it even introduced an imbalance in the medial-lateral direction in girls affected by adolescent idiopathic scoliosis (Chow et al., 2006). Besides the load itself, the carrying method also affected the body posture. Kinoshita (1985) found that an asymmetrical carrying method caused more spinal tilt in level walking, whereas Troussier and coworkers (1994) found that there was a risk that it could cause low back pain. Pascoe and coworkers (1997) also found that an asymmetrical school bag carrying method, 
whether the child was carrying either a single-strap backpack or a shoulder-supported athletic bag, significantly increased lateral spinal deviation during level walking.

In Hong Kong, schools and living places are often multi-stories buildings, and thus stair use is a common daily functional activity. Previous studies have shown that stair climbing and level walking necessitate two different kinds of gait (Loy and Voloshin, 1991; McFadyen and Winter, 1998). Because one has to propel the body forward and also upward or downward in stair use, doing so with a heavy school bag may result in increased dynamic loading on the body. Hong and coworkers (2003) found that a load of $10 \%$ body weight or more produced a significant forward spinal lean when ascendinga staircase. Moreover, greater spinal motion in the sagittal plane was observed when the subjects carried a single-strap shoulder-supported athletic bag, which represented an asymmetrical carrying method. In kinetics, Hong and Li(2005) found that increased peak plantar force was used during the descent of a staircase with a load in an athletic bag which represented $10 \%$ body weight. However, there have been few studies reporting the spinal biomechanics in the frontal plane during stair use.

It is generally understood that stair use, especially when ascendinga staircase, is more physically demanding compared to level walking. The demands of load carriage and carrying method may impose a greater challenge to the spine, and may thus lead to a higher risk of spinal symptoms. While the effect on sagittal plane spinal motion and plantar force has been demonstrated, the effect on the frontal plane spinal motion has not been investigated. This study reported on the effects of load carriage and school bag type on spinal postureduring stair use by children.

\section{Methods:}


Thirteen male children (mean \pm S.D.: age: $12.2 \pm 1.0$ yrs; mass: $47.1 \pm 9.7 \mathrm{~kg}$; height: $159.7 \pm 9.7 \mathrm{~cm}$ ) participated in this study. The test was carried out at a 33-step staircase situated in-between the audience seating at the university sports field. All participants were free of injury on the testing day, and had no history of injury that caused them to have an abnormal gait or difficulties when using stairs. Completed consent forms from the participants and their parents were collected before the test. Participants were each required to dress in a black tight $\mathrm{t}$-shirt and black shorts, with six reflective skin markers attached at the left and right shoulder, hip and toe. The black dressing and the reflective markers were to facilitate the automatic video image digitization when we analyzed the video data in the motion analysis software.

In each of the trials each participant ascended and descended the staircase carrying different loads in school bags of a different type. He started at the bottom of the 33-step staircase, walked up to the top and then walked down to the bottom at his natural cadence; they were required to do thisthree times. A total of eight trials from a combination of four different loads in two different school bag types were performed by each participant in a random sequence. The four load conditions equaled $0 \%, 10 \%$, $15 \%$ and $20 \%$ of the participant's body weight. Percentage weight instead of absolute weight was used in order to achieve normalization across the range of participants. The required weight was prepared by filling the school bag with objects that students usually bring to school, such as books, pencil box, drawing material, PE T-shirt and shoes. The two types of school bag were: (1) a single-strap athletic bag; and (2) a double-strap backpack. In the trials with the single-strap athletic bag, the bag was placed on the left with the strap across the right shoulder - this represented an asymmetrical carrying method (Figure 1a), with the left as the loading side and the right as the supporting side. In the trials with the double-strap backpack, the fillings in the 
bag were arranged in a symmetrical way, with a strap across each shoulder - this represented a symmetrical carrying method (Figure 1b).

A video camera (JVC DVL9800, Japan) was positioned at the bottom of the staircase, viewing upwards, to record the spinal movements in a frontal plane with a $50 \mathrm{~Hz}$ filming rate and a $1 / 250$ s shutter speed. The camera zoom level was adjusted to produce a full-picture view when the participant stepped on the middle of the staircase for one complete gait cycle (from the 15 th to the 17 th step). Before the experiment, each subject was instructed to stand on the 16th step in his anatomical position without carrying any load, and such posture was videotaped to define the initial vertical neutral position. The films were captured and saved in a computer. Video data of one complete gait cycle as identified by the moment of foot strikeas indicated by the markers at the toe was trimmed during every ascending and descending trial. The video data were digitized by a motion analysis system (Ariel Performance Analysis System, USA). For the purposes of this experiment the spine was defined as being the line joining the mid-point between the shoulders and the mid-point between the hips, and the spinal posture was defined as the angle between the spine and the initial vertical position of each participant. The maximum spinal tilting angle to the left and to the right, and the range of the spinal tilting angle were averaged over the participants at each load and with each school bag type when they ascended and descendedthe staircase.

Both for the ascent and the descentof the staircase, a two-way multivariate analysis of variance (bag type $\times$ load) with repeated measures (MANOVA) was applied on the dependent variables in order to identify any significant effects caused by bag type and load. The analysis was conducted with a statistical analysis software (Statistical Package for the Social Sciences, USA). If an interactive effect was found, a stratified 
analysis of variance (ANOVA) was conducted to demonstrate the load effect on each bag type (for all parameters), and the bag type effect on each load (for a range of spinal motion only), with Tukey pairwise comparisons conducted between the $0 \%$ load and the other loads. If not, an ANOVA on each main effect was conducted. In order to further demonstrate the symmetry of spinal posture, independent t-tests were conducted between the maximum tilting angle to the left and to the right for each bag type and load. Independent t-tests were also conducted for the ascent and the descent ofthe staircase in every pair of parameters. The statistical significance was set at a 95\% level of confidence.

\section{Results:}

Table 1 shows the mean and standard deviation of the spinal posture parameters, including the maximum spinal tilting angle to the left, the maximum spine tilting angle to the right, and the range of the spine tilting angle at each load with each school bag type in ascending and descending the staircase, respectively. The MANOVA showed a significant interactive $($ bag type $\times$ load) effect (Wilk's lambda $=0.664, \mathrm{~F}=2.646, \mathrm{p}=$ 0.023). Therefore, a stratified ANOVA was conducted.

With regard to ascending the staircase, an ANOVA showed that a significant difference was found in the maximum tilting angle to the left and also to the right for a single-strap athletic bag $(\mathrm{p}<0.05)$. Tukey pairwise comparisons showed that the maximum tilting angle to the left (the loading side), was significantly reduced from 3.9 degrees to 1.5 degrees when the load was increased from $0 \%$ to $20 \%$ body weight $(\mathrm{p}<0.05)$. The maximum tilting angle to the right (the supporting side), was significantly increased from 6.0 degrees to 8.3 degrees when the load was increased from $0 \%$ to $15 \%$ body weight $(\mathrm{p}<0.05)$, and it increased to 8.6 degrees when the load was increased from $0 \%$ 
to $20 \%$ body weight $(\mathrm{p}<0.05)$. No significant difference was found for the maximum spinal tilting angles for the double-strap backpack, and also for the range of spinal motion for both designs of school bag. For the single-strap school bag, independent t-tests showed that there was a significant difference between the tilting angles to the left (the loading side) and to the right (the supporting side) when the load reached $15 \%$ and $20 \%$ body weight $(\mathrm{p}<0.05)$.

In descending the staircase, the tilting angles and the range of spinal motions were generally smaller than those during ascending the staircase. An ANOVA showed no significant difference between different loads and types of school bag.

Tukey pairwise comparisons showed that there were significant differences between each pair of parameters among ascending and descendingthe staircase, except that the spinal tilting angle was to the left with a $15 \%$ and $20 \%$ load in a single-strap athletic bag. 


\section{Discussion:}

The range of spinal motion did not differ among loads in relation either to the single-strap athletic bag or the double-strap backpack both when ascending and descendingthe staircase. However, in each load $\times$ carrying method combination, it was found to be greater when ascendingthe staircase. The range was about 4.5 to 7.2 degrees when descendingthe staircase and 9.9 to 11.9 degrees when ascendingthe staircase. The range of motion did not differ between the two types of school bag with regard to all of the loads. For the double-strap backpack, which represented a symmetrical carrying method, the spinal tilting angles to the left and to the right did not differ either between each other or among the loads both as to the ascent and the descent of the staircase. However, it was significantly increased from 1.9 to 2.8 degrees in the descent of the staircase to 5.3 to 6.5 degrees in the ascent of the staircase. These findings suggest that the spinal motion was generally much larger during ascending than it was during descending. The load effect was not significant. Moreover, the similar spinal tilting angles to the left and to the right with a double-strap backpack suggested that this carrying method is symmetrical in the human frontal plane.

Before this investigation, the authors did not expect if a spinal tilt would be to the loading side or the support side when a single-strap athletic bag is being carried. The results of this study showed that the spinal tilt was to the support side (right) when the load reached $15 \%$ and $20 \%$ of the body weight. Generally, the tilting angles during the ascent of the staircase were higher than the descent.

In regard to level walking, Pascoe and coworkers (1997) studied the effect on lateral spinal tilt in 10 subjects (age $=11-13$ years) who each carried different school bags with a load of $17.6 \%$ body weight. They reported that the lateral spinal tilt was much 
greater when an asymmetrical carrying method was used than it was with a symmetrical carrying method. When walking without a load, the lateral spinal tilt was 1.9 degrees. When carrying a load in a two-strap backpack, the lateral spinal tilt was about 2.1 degrees and there was no significant difference. However, when the load was placed in a one-strap backpack or in a one-strap athletic bag, the lateral spinal tilt was significantly increased to 8.5 and 8.3 degrees, respectively. With regard to stair use, Hong and coworkers (2003) found that load carriage in an asymmetrical school bag caused a greater amount of spinal sagittal motion. In kinetics, a significant increase of peak plantar force was found when the load was $10 \%$ body weight in an asymmetrical load-carrying method when ascending a staircase; however, such a significant increase was found when the load reached $15 \%$ body weight when a symmetrical load-carrying methodwas used (Hong and Li, 2005).

In this study, significant spinal tilt was observed both in the ascent and the descent of the staircase with a load in a single-strap athletic bag. Moreover, the range of spinal motion was 9.9 to 11.9 degrees when ascendingthe staircase, which was greater than that in level walking (8.5 degrees), as was reported by Pascoe and coworkers (1997). These results, together with the findings in previous studies, suggest that an asymmetrical carrying method imposes greater stress on the spine, especially when ascending a staircase with a load of $15 \%$ body weight or more. The nature of the locomotion in stair use is different from that used in level walking. In level walking, a person stays at the same horizontal level; he therefore propels his body (and thus his center of gravity) in only a forward direction. In stair use, a person needs to propel his body forwards and also either upwards or downwards. In doing this, he has to bend his legs to raise or lower one side of the body to land on the next step. This produces greater spinal motion when compared to level walking. The tilt was more significant when 
there was a heavy load ( $>15 \%$ body weight) in an asymmetrical carrying method.

The spinal tilt was to the supported side (the side with the school bag strap on the shoulder) instead of to the loading side. This is the human adaptation for minimizing the disturbance to the balance and stability of the body's center of mass. When a single-strap athletic bag is loaded on the left, the center of gravity of the person plus the school bag shifts to the left. This introduces posture instability; the person has, therefore, to tilt the body to the right in order to shift the center of gravity back to the middle of the supporting base, which is between both feet. Doing this over a prolonged period requires repetitive activation of the spine's stabilizing muscles. This may lead to muscle pain, low back pain and chronic injuries. Therefore, we suggest that further study on spine-stabilizing muscle activity and fatigue is required.

Although a double-strap backpack is symmetrical in the frontal plane, it is still asymmetrical in the sagittal plane; this is because all the loads are at the posterior aspect of the human spine. There was also another recent study which proposeda modified double backpack design in which part of the load would be placed at the chest area (Kim et al., 2008). Such a design should successfully reduce the stress on the spine. Chow and colleagues (2007) suggested that a backpack load would cause the flattening of the lumbar lordosis and the upper thoracic kyphosis, and thus produce immediate changes to the spinal curvature. They also suggested that a consistent shifting of the load position could help to solve the problem of the stressing of the spine (Chow et al., 2010).We therefore believe that a different method of carrying a single-strap athletic bag should be less harmful. We therefore suggest thatfurther research thereon would be very worthwhile. 


\section{Conclusion:}

This study suggested that the spinal posture was not altered when climbing stairs with a double-strap backpack. However, a significant spinal tilt to the support side was observed when a single-strap athletic bag was being carried. The spinal tilt was much more significant when the load was $15 \%$ body weight or more. We therefore conclude that a symmetrical backpack or an asymmetrical single-strap athletic bag with a load not exceeding $10 \%$ should be recommended for school children in order to avoid spinal posture alteration during stair use. Furthermore, we also suggest that further sudy of muscle activity be carried out.

\section{References:}

1. Chansirinukor, W., Wilson, D., Grimmer, K. and Dansie, B., 2001. Effects of backpacks on students: measurement of cervical and shoulder posture. Australian Journal of Physiotherapy, 47(2), 110-116.

2. Chow, D.H., Kwok, M.L., Cheng, J.C., Lao, M.L., Holmes, A.D., Au-Yang, A., Yao, F.Y. and Wong, M.S., 2006. The effect of backpack weight on the standing posture and balance of schoolgirls with adolescent idiopathic scoliosis and normal controls. Gait and Posture, 24(2), 173-181. 
3. Chow, D.H.K., Leung, K.T.Y. and Holmes, A.D., 2007. Changes in spinal curvature and proprioception of schoolboys carrying different weights of backpack. Ergonomics, 50(12), 2148-2156.

4. Chow, D.H.K., Ou, Z.Y., Wang, X.G. and Lai, A., 2010. Short-term effects of backpack load placementon spine deformation and repositioning error in schoolchildren. Ergonomics, 53(1), 56-64.

5. Hong, Y. and Brueggemann, G., 2000. Changes of gait pattern in 10 years old children during treadmill walking with increasing loads. Gait and Posture, 11(3), 245-259.

6. Hong, Y. and Cheung, C.K., 2003. Gait and posture responses to backpack load during level walking in children. Gait and Posture, 17(1), 28-33.

7. Hong, Y., Lau, T.C. and Li, J.X., 2003.Effects of loads and carrying methods of school bags on movement kinematics of children during stair walking. Research in Sports Medicine, 11(1), 33-49.

8. Hong, Y. and Li, J.X., 2005. Influence of load and carrying methods on gait phase and ground reactions in children's stair walking. Gait and Posture, 22(1), 63-68.

9. Hong, Y., Li, J.X. and Fong, D.T.P., 2008.Effect of prolonged walking with backpack loads on trunk muscle activity and fatigue in children. Journal of Electromyography and Kinesiology, 18(6), 990-996.

10. Hong, Y., Li, J.X., Wong, A.S.K. andRobinson, P.D., 2000. Effects of loads carriage on heart rate, blood pressure and energy expenditure in children. Ergonomics, 43(6), 717-727.

11. Hong Kong Society for Child Health and Development, 1998. The weight of school bags and its relation to spinal deformity. Hong Kong: The Department of Orthopaedic Surgery, University of Hong Kong, The Duchess of Kent Children's Hospital. 
12. Johnson, R.F., Knapik, J.J. and Merullo, D.J., 1995. Symptoms during load carrying: effects of mass and load distribution during a 20-km road march. Perceptual and Motor Skills, 81(1), 331-338.

13. Kim, M.H., Yi, C.H., Kwon, O.Y., Cho, S.H. and Yoo, W.G., 2008. Changes in neck muscle electromyography and forward head posture of children when carrying schoolbags. Ergonomics, 51(6), 890-901.

14. Kinoshita, H., 1985. Effects of different loads and carrying systems on selected biomechanical parameters describing walking gait. Ergonomics, 28(9), 1347-1362.

15. Lai, J.P. and Jones, A.Y., 2001. The effect of shoulder-girdle loading by a school bag on lung volumes in Chinese primary school children. Early Human Development, 62(1), 79-86.

16. Li, J.X., Hong, Y. and Robinson, P.D., 2003. The effect of load carriage on movement kinematics and respiratory parameters in children during walking. European Journal of Applied Physiology, 90(1-2), 35-43.

17. Loy, D.J. and Voloshin, A.S., 1991. Biomechanics of stair walking and jumping. Journal of Sports Science, 9(2), 137-149.

18. Mackenzie, W.G., Sampath, J.S., Kruse, R.W. andSheir-Neiss, G.J., 2003. Backpacks in children. Clinical Orthopaedics and Related Research, (409), 78-84.

19. McFadyen, B.J. and Winter, D.A., 1998. An integrated biomechanical analysis of normal stair ascent and descent. Journal of Biomechanics, 21(9), 733-744.

20. Negrini, S. and Carabalona, R., 2002. Backpacks on! Schoolchildren's perceptions of load, associations with back pain and factors determining the load. Spine, 27(2), $187-195$.

21. Pascoe, D.D., Pascoe, D.E., Wang, Y.T., Shim, D.M. and Kim, C.K., 1997. 
Influence of carrying book bags on gait cycle and posture of youths. Ergonomics, 40(6), 631-641.

22. Pau, M. and Pau, M., 2010.Postural sway modifications induced by backpack carriage in primary school children: a case study in Italy. Ergonomics, 53(7), 872-881.

23. Sheir-Neiss, G.I., Kruse, R.W., Rahman, T., Jacobson, L.P. and Pelli, J.A., 2003. The association of backpack use and back pain in adolescents. Spine, 28(9), 922-930.

24. Trevelyan, F.C. and Legg, S.J., 2010. The prevalence and characteristics of back pain among school children in New Zealand. Ergonomics, 53(12), 1455-1460.

25. Troussier, B., Davoine, P., de Gaudemaris, R., Fauconnier, J. and Phelip, X., 1994. Back pain in school children a study among 1178 pupils. Scandinavian Journal of Rehabilitation Medicine, 26(3), 143-146.

26. Wiersema, B.M., Wall, E.J. and Foad, S.L., 2003. Acute backpack injuries in children. Pediatrics, 111(1), 163-166.

\section{Figure legend:}

The two carrying methods investigated in this study: (a) the asymmetrical carrying method with a single-strap athletic bag, with the school bag placed on the left (loading side) and the school bag strap on the right shoulder (supporting side); (b) the symmetrical carrying method with a double-strap backpack. 
Table 1 - Maximum and range of spine tilting angles for stairs ascending and descending with loads in single- and double-strap school bag

\begin{tabular}{|c|c|c|c|c|c|c|c|c|c|}
\hline \multirow[b]{2}{*}{ Load (\% body weight) } & \multicolumn{3}{|c|}{ Single-strap athletic bag } & \multicolumn{3}{|c|}{ Double-strap backpack } & \multicolumn{3}{|c|}{ Range of spinal motion (degree) } \\
\hline & $\begin{array}{l}\text { Max. angle - } \\
\text { left (degree) }\end{array}$ & $\begin{array}{l}\text { Max. angle - } \\
\text { right (degree) }\end{array}$ & $\begin{array}{l}\mathrm{p} \text { value } \\
\text { of t-test }\end{array}$ & $\begin{array}{l}\text { Max. angle - } \\
\text { left (degree) }\end{array}$ & $\begin{array}{l}\text { Max. angle - } \\
\text { right (degree) }\end{array}$ & $\begin{array}{l}\mathrm{p} \text { value } \\
\text { of } \mathrm{t} \text {-test }\end{array}$ & $\begin{array}{l}\text { Single-strap } \\
\text { athletic bag }\end{array}$ & $\begin{array}{l}\text { Double-strap } \\
\text { backpack }\end{array}$ & $\begin{array}{l}\mathrm{p} \text { value of } \\
\text { t-test }\end{array}$ \\
\hline \multicolumn{10}{|l|}{$\underline{0 \%}$} \\
\hline Stairs ascending & $3.9(2.1)$ & $6.0(3.5)$ & .084 & $5.5(2.1)$ & $5.9(2.2)$ & .656 & $9.9(2.7)$ & $11.4(2.7)$ & .183 \\
\hline Stairs descending & $1.5(1.8)$ & $3.6(1.9)$ & $.008 *$ & $1.9(1.6)$ & $2.6(1.7)$ & .277 & $5.1(1.5)$ & $4.5(1.3)$ & .237 \\
\hline$p$ value of t-test & $.005^{*}$ & $.044^{*}$ & & $<.001 *$ & $<.001 *$ & & $<.001^{*}$ & $<.001 *$ & \\
\hline \multicolumn{10}{|l|}{$\underline{10 \%}$} \\
\hline Stairs ascending & $4.0(2.1)$ & $6.1(3.8)$ & .090 & $5.4(2.1)$ & $6.5(3.1)$ & .290 & $10.1(3.8)$ & $11.9(2.7)$ & .167 \\
\hline Stairs descending & $1.1(1.9)$ & $3.6(2.1)$ & $<.001 *$ & $2.7(0.9)$ & $2.1(1.6)$ & .290 & $4.7(2.1)$ & $4.8(1.3)$ & .957 \\
\hline$p$ value of t-test & $.001 *$ & $.050 *$ & & $<.001^{*}$ & $<.001 *$ & & $.001 *$ & $<.001 *$ & \\
\hline \multicolumn{10}{|l|}{$\underline{15 \%}$} \\
\hline Stairs ascending & $2.7(3.4)$ & $8.3(4.4)$ & $.001 *$ & $5.4(2.0)$ & $5.3(1.8)$ & .858 & $11.0(4.1)$ & $10.7(2.5)$ & .850 \\
\hline Stairs descending & $2.1(2.4)$ & $4.2(2.4)$ & $.036^{*}$ & $2.5(1.3)$ & $2.2(1.4)$ & .511 & $6.3(1.9)$ & $4.7(1.4)$ & $.020 *$ \\
\hline$p$ value of t-test & .613 & $.008^{*}$ & & $<.001 *$ & $<.001 *$ & & $.001^{*}$ & $<.001 *$ & \\
\hline \multicolumn{10}{|l|}{$20 \%$} \\
\hline Stairs ascending & $1.5(3.2)$ & $8.6(3.1)$ & $<.001 *$ & $5.4(1.6)$ & $5.7(2.5)$ & .769 & $10.1(2.0)$ & $11.1(1.9)$ & .240 \\
\hline Stairs descending & $2.5(2.6)$ & $4.7(2.7)$ & $.046^{*}$ & $2.6(1.0)$ & $2.8(2.1)$ & .710 & $7.2(2.6)$ & $5.4(1.3)$ & $.032 *$ \\
\hline$p$ value of t-test & .396 & $.002 *$ & & $<.001 *$ & $.004 *$ & & $.004 *$ & $<.001 *$ & \\
\hline
\end{tabular}

*= Significant difference, $\mathrm{p}<0.05$. Statistical analysis program show only to $\mathrm{p}<0.001$. 


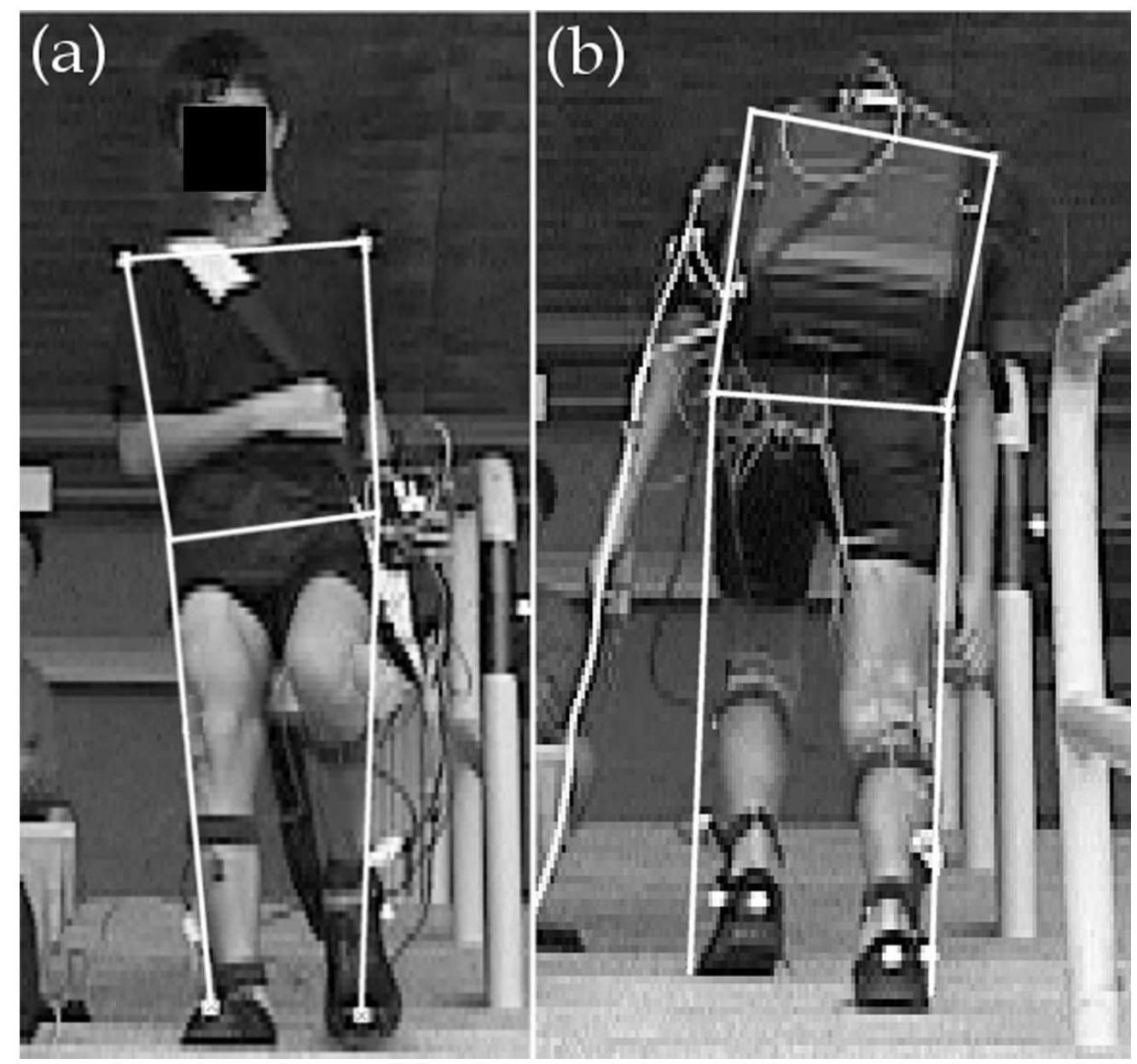

The two carrying methods investigated in this study: (a) asymmetrical carrying method with a single-strap athletic bag, with the school bag placed on the left (loading side) and the school bag strap on the right shoulder (supporting side), (b) symmetrical carrying method with a double-strap backpack

$101 \times 95 \mathrm{~mm}(300 \times 300$ DPI $)$ 